\title{
A Voz do Usuário: a Importância de Sua Participação na Construção do Sistema Único Saúde
}

\author{
Machado, Diego da Silva; Pere, Letícia Gabrielly Medeiros; Pereira, Francyelle de \\ Mello; Lino, Iven Giovanna Trindade; Luz, Ananda de Mello; Souza, Rodrigo \\ Domingos de; Mendonça, Margarete Knoch \\ Universidade Federal do Mato Grosso do Sul _ diegomachadoenf2015@gmail.com
}

Introdução: a coleta de opiniões sobre a satisfação dos usuários, na saúde, desperta interesse e é um importante gerador de informações fidedignas para o planejamento dos cuidados, e qualidade dos serviços oferecidos, auxiliando no aprimoramento dos mesmos. Esta experiência visa atender a necessidade da atenção básica de aproximar o usuário com as equipes das unidades de saúde. Este trabalho foi desenvolvido durante o curso de enfermagem. Objetivos: Avaliar a qualidade dos serviços oferecidos pela equipe multiprofissional na unidade básica de saúde da família (UBSF), a fim de fortalecer o acolhimento e a participação ativa dos usuários na construção de SUS; avaliar a relação entre as respostas e o nível socioeconômico/escolaridade dos sujeitos. Metodologia: $1^{\circ}$ momento: Foi elaborado um questionário semi-estruturado, com questões de múltipla escolha referente ao atendimento prestado aos usuários: duração da consulta, periodicidade das visitas domiciliares, relação profissional de saúde-usuário, qualidade no atendimento nos vários setores na unidade, relação gestor-usuário, escolaridade e renda familiar e um espaço para sugestões e críticas. Os funcionários da recepção foram orientados quanto ao preenchimento e deposito na urna. $2^{\circ}$ momento: As informações coletadas foram transcritas em um quadro, repassado ao gerente da unidade, que juntamente com equipe multiprofissional, elaborou proposta a fim de solucionar os problemas levantados. Resultados: Verificou-se que o nível de escolaridade é predominantemente nível fundamental incompleto e a renda familiar mensal média fica em torno de um salário mínimo. Observou-se um elevado grau de satisfação dos usuários da UBSF estudada, quanto a: duração da consultas dos profissionais de nível superior, periodicidade das visitas domiciliares, relação profissional de saúde-usuários, acolhimento e humanização, qualidade no atendimento nos vários setores da unidade, relação gestorusuário. Indica a existência de uma associação entre a escolaridade e nível sócio econômico e o grau de satisfação em relação ao serviço de saúde. Conclusão: a experiência foi exitosa, pois mostrou a ótica do usuário, além de ter um impacto positivo quanto a aproximação entre o profissional de saúde e o usuário, o estabelecimento de vínculos e o reconhecimento do usuário como protagonista da atenção e do cuidado a saúde. Porém, despertou também o interesse em pesquisar outras formas de auscultar a voz do usuário buscando outras dimensões das condições de vida e de adoecimento, como aspectos individuais e emocionais.

Machado, Diego da Silva; Pere, Letícia Gabrielly Medeiros; Pereira, Francyelle de Mello; Lino, Iven Giovanna Trindade; Luz, Ananda de Mello; Souza, Rodrigo Domingos de; Mendonça, Margarete Knoch. A Voz do Usuário: a Importância de Sua Participação na Construção do Sistema Único Saúde.. In: Anais do

Congresso Internacional de Humanidades \& Humanização em Saúde [= Blucher Medical Proceedings, num.2, vol.1]. São Paulo: Editora Blucher, 2014. ISSN 2357-7282

DOI 10.5151/medpro-cihhs-10842 